\title{
Revisiting corneal topography for the diagnosis of keratoconus: use of Rabinowitz's KISA\% index
}

This article was published in the following Dove Press journal:

Clinical Ophthalmology

25 January 2012

Number of times this article has been viewed

\section{Mohammad Reza \\ Sedghipour \\ Afshin Lotfi Sadigh \\ Behzad Fallahi Motlagh \\ Department of Ophthalmology, \\ Tabriz University of Medical Sciences, \\ Tabriz, Iran}

Correspondence: Afshin Lotfi Sadigh

Department of Ophthalmology,

Tabriz University of Medical Sciences,

Tabriz, Iran

Tel/fax +989141160572

Email afshinlotfi48@gmail.com
Background: Numerous videokeratographic methods are used in the diagnosis of keratoconus. The purpose of this study was to compare the sensitivity and specificity of the KISA\% index with the keratometry $(\mathrm{K})$ value, inferior-superior (I-S) value, relative skewing of the steepest radial axes (SRAX), and keratometric astigmatism (AST) indices in 25 patients presenting with bilateral keratoconus.

Methods: Twenty-five patients presenting with bilateral keratoconus were enrolled. Fifty eyes from 25 healthy individuals without corneal abnormalities were used as controls. The clinical diagnosis of keratoconus was made by observation of scissors reflex at retinoscopy and characteristic slit lamp findings. Corneal topographic analysis was performed in each eye to calculate the $\mathrm{K}$ value, I-S value, AST, and SRAX indices.

Results: The keratoconus percentage index (KISA\%) was significantly more sensitive and specific than the other indices examined. Furthermore, it was significantly better at predicting positive and negative results than the other indices included in the study.

Conclusion: The current research suggests that KISA\% could be used to detect/diagnose keratoconus but further studies are required to confirm the specificity and sensitivity of KISA\% for the detection of early-stage disease and keratoconus suspects.

Keywords: cornea, keratoconus, KISA\% index

\section{Introduction}

Keratoconus, a degenerative disorder characterized by thinning of the cornea, can result in substantial distortion of vision. Clinical diagnosis should involve researching a patient's medical history, refraction, keratometry, and slit-lamp examination to evaluate the status of the cornea. ${ }^{1}$ Corneal topography, also known as photokeratoscopy or videokeratography, is a noninvasive imaging technique used to map the surface curvature of the cornea. ${ }^{2}$ It has been argued that topography should be used in conjunction with manual keratometry and not as an alternative. ${ }^{1}$ However, it has been demonstrated that corneal topography provides a more definitive diagnosis, detecting the disorder during the early stages despite normal results after slit-lamp examination and keratometry, ${ }^{3}$ that it can be used to detect keratoconus suspects, ${ }^{4}$ and it is considered obligatory for pre-operative evaluation before refractive surgery is carried out. ${ }^{5}$

Mathematical indices are used to determine the disorder with high specificity and sensitivity. ${ }^{5}$ Solis-Vivanco et al compared corneal topography with clinical diagnosis, which serves as the gold standard, reporting that topography indices had a sensitivity 
of $87 \%$ and a specificity of $92 \%$ in terms of diagnosing keratoconus. ${ }^{6}$ Using a combination of four topography indices, namely the central keratometry $(\mathrm{K})$ value, the inferior-superior (I-S) value, relative skewing of the steepest radial axes (SRAX), and keratometric astigmatism (AST), Rabinowitz demonstrated that corneal topography yielded a false-positive rate of $0.5 \%$ and false-negative rate of $2.5 \%$ in the diagnosis of keratoconus. ${ }^{7}$

It has been reported that no single videokeratoscopic index is capable of discriminating between groups of individuals with clinical signs of disease and first-degree relatives of patients with keratoconus. ${ }^{8}$ However, a study carried out by Rabinowitz and Rasheed compared a new index, keratoconus percentage index (KISA\%), derived from the aforementioned topographic parameters (K value, I-S value, SRAX, and AST) with modified Rabinowitz/McDonnell (K value and I-S value) and Maeda/Klyce (keratoconus prediction index $[\mathrm{KCI}]$ and $\mathrm{KCI} \%$ ) indices, and demonstrated that with a cut-off value of $100 \%$, KISA $\%$ yielded an improvement in the rate of correct diagnosis $(99.6 \%) .{ }^{9}$ In order to further elucidate the diagnostic accuracy of the KISA\% index, the present study compared the K value, I-S value, SRAX, and AST corneal topographic indices in 25 individuals suffering from bilateral keratoconus.

\section{Materials and methods}

Twenty-five patients presenting with bilateral keratoconus between April and December 2007 were enrolled in the study. Informed consent was obtained, and the subjects' age, gender, family history, past medical history, and details of ophthalmologic surgery were recorded. The inclusion criterion was clinical detection of keratoconus, and exclusion criteria were recent history of contact lens use, past history of eye surgery, and the presence of a corneal ulcer or other corneal diseases. ${ }^{10,11}$ Fifty eyes from 25 healthy individuals without corneal abnormalities were used as controls. All subjects were subjected to examination by slit-lamp, and direct ophthalmoscopic and retinoscopic examinations. The clinical diagnosis of keratoconus was made by observation of scissors reflex at retinoscopy and characteristic slit lamp findings, eg, Fleischer ring and Vogt's striae. ${ }^{12-14}$ Using an EyeSys videokeratoscope (VK EyeSys Laboratories, Houston, TX), corneal topographic analysis was performed in each eye to calculate the $\mathrm{K}$ value, I-S value, AST, and SRAX indices. KISA\% was calculated using the following formula:

$$
\mathrm{KISA} \%=\frac{(\mathrm{K}) \times(\mathrm{I}-\mathrm{S}) \times(\mathrm{AST}) \times(\mathrm{SRAX}) \times 100}{300}
$$

Absolute values were used in the calculation and values less than one were replaced with a value of one. $\mathrm{K}$ values less than 47.2 D were replaced with a value of one and those greater than 47.2 D were replaced with $(\mathrm{K}-47.2)$ as detailed in Rabinowitz and Rasheed. ${ }^{9}$

Data were expressed as the mean \pm standard deviation. Statistical analyses were performed using SPSS for Windows (v 11.0; SPSS Inc, Chicago, IL) using the independent samples $t$-test and Pearson's Chi-square test. Statistical significance was accepted at $P<0.05$. Cut-off values of variables $(\mathrm{K}$ value $>47.2 \mathrm{D}, \mathrm{I}-\mathrm{S}$ value $>1.4 \mathrm{D}$, AST $>1.5 \mathrm{D}, \mathrm{SRAX}$ index $>21^{\circ}, \mathrm{KISA} \%>100 \%$ ) reported by Rabinowitz ${ }^{7}$ and Rabinowitz and Rasheed ${ }^{9}$ for the determination of keratoconus were used to calculate the sensitivity, specificity, and positive and negative predictive values for each variable in the diagnosis of keratoconus. According to the aforementioned cut-off values of the variables, a positive predictive value was defined as the proportion of patients with positive test results who were correctly diagnosed based on the clinical diagnosis of keratoconus. Moreover, a negative predictive value was defined as the proportion of patients with negative test results that were correctly diagnosed. ${ }^{9,15}$

\section{Results}

The mean age of the patients was $25.84 \pm 7.04$ years and the mean age of the control group was $24.84 \pm 6.08$ years $(P=0.449)$. Male:female ratios were $11: 14$ in the keratoconus group and 13:12 in the control group; both groups were sex-matched (Chi-square test, $P=0.571$ ). The $\mathrm{K}$ value, I-S value, SRAX index, and KISA\% were higher in the experimental group than the control group, but the I-S value and SRAX index demonstrated greater variation among keratoconus patients (Table 1). There were no statistically significant differences between the K value, I-S value, AST, SRAX indices, and KISA\% among patients with respect to gender $(P>0.1)$.

Table I Topographic index values

\begin{tabular}{lccl}
\hline & Patients & Control & P value \\
\hline K value & $54.68 \pm 8.78$ & $46.48 \pm 1.78$ & $<0.01$ \\
I-S value & $5.62 \pm 7.04$ & $1.91 \pm 1.12$ & $<0.001$ \\
AST & $4.92 \pm 2.81$ & $4.26 \pm 2.41$ & 0.209 \\
SRAX & $13.88 \pm 18.68$ & $5.32 \pm 6.41$ & 0.003 \\
KISA\% & $10126.67 \pm 13662.47$ & $21.35 \pm 16.63$ & $<0.01$ \\
\hline
\end{tabular}

Abbreviations: $\mathrm{K}$, keratometry; I-S, inferior-superior; AST, keratometric astigmatism; SRAX, relative skewing of the steepest radial axes; KISA\%, keratoconus percentage index. 
Table 2 Measured parameters of topographic indices

\begin{tabular}{lllll}
\hline Variable & $\begin{array}{l}\text { Sensitivity } \\
\text { (\%) }\end{array}$ & $\begin{array}{l}\text { Specificity } \\
(\%)\end{array}$ & $\begin{array}{l}\text { Positive } \\
\text { predictive } \\
\text { value (\%) }\end{array}$ & $\begin{array}{l}\text { Negative } \\
\text { predictive } \\
\text { value (\%) }\end{array}$ \\
\hline K value & 82 & 68 & 71.93 & 79.09 \\
I-S value & 74 & 38 & 54.41 & 59.38 \\
AST & 88 & 10 & 49.44 & 45.45 \\
SRAX & 24 & 96 & 85.71 & 55.81 \\
KISA\% & 96 & 100 & 100 & 96.15 \\
\hline
\end{tabular}

Abbreviations: $\mathrm{K}$, keratometry; I-S, inferior-superior; AST, keratometric astigmatism; SRAX, relative skewing of the steepest radial axes; KISA\%, keratoconus percentage index.

Several topographic indices have been developed for the determination of keratoconus. Comparing the sensitivity and specificity of each of the studied topographic indices revealed that while the $\mathrm{K}$ value and AST demonstrated $>80 \%$ sensitivity and the SRAX demonstrated $>90 \%$

A

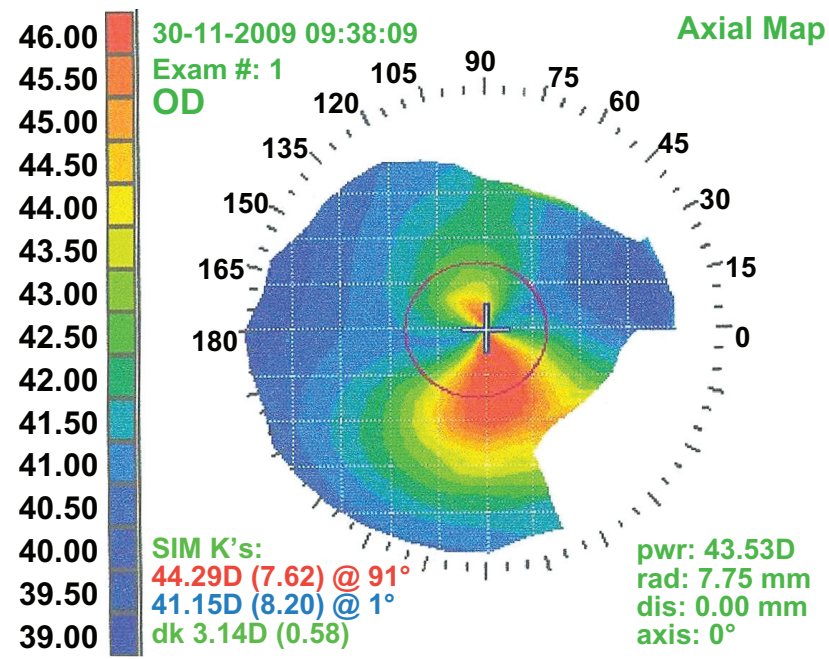

B

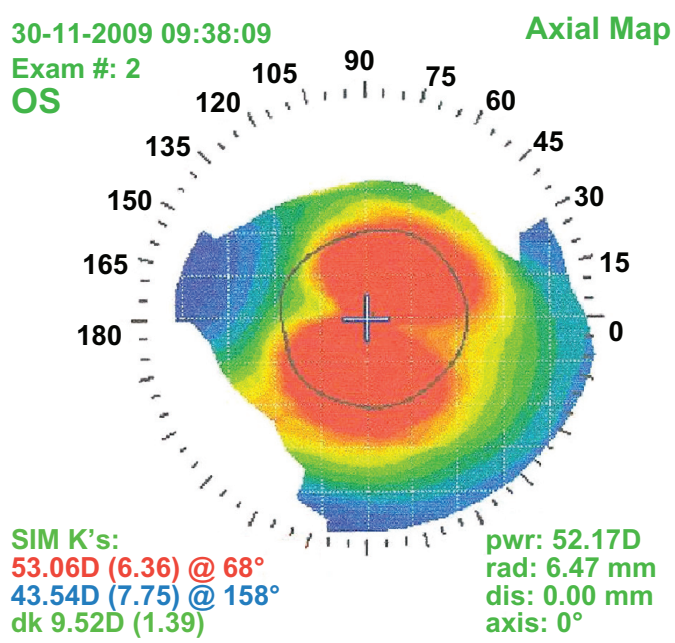

\begin{tabular}{|l}
46.00 \\
45.50 \\
45.00 \\
44.50 \\
44.00 \\
43.50 \\
43.00 \\
42.50 \\
42.00 \\
41.50 \\
41.00 \\
40.50 \\
40.00 \\
39.50 \\
39.00
\end{tabular} \mid

specificity, SRAX and AST indices had the lowest sensitivity and specificity, respectively. KISA\% was the only index with specificity and sensitivity $>90 \%$ (Table 2 ). Furthermore, KISA\% was the only index demonstrating positive and negative predictive values $>95 \%$. Corneal topography images of two patients with keratoconus are shown in Figure 1A-D.

\section{Discussion}

Corneal topography is effective in the early diagnosis of keratoconus, irrespective of clinical symptoms, ${ }^{3}$ and when compared to clinical examination has been reported to have a sensitivity of $87 \%$ and a specificity of $92 \%$ in terms of diagnosing the disorder. ${ }^{6}$ However, this study demonstrates that there is great variation among different indices in terms of the sensitivity, specificity, and the ability to predict

C

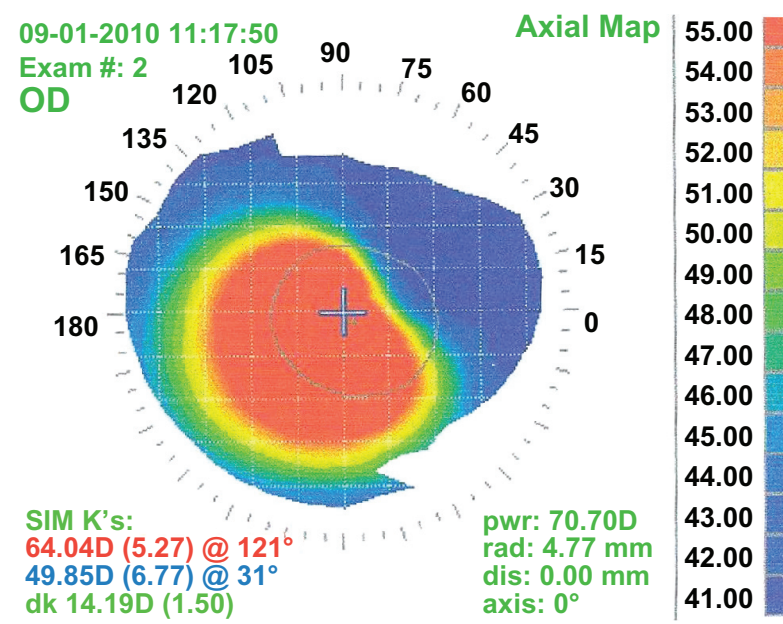

D

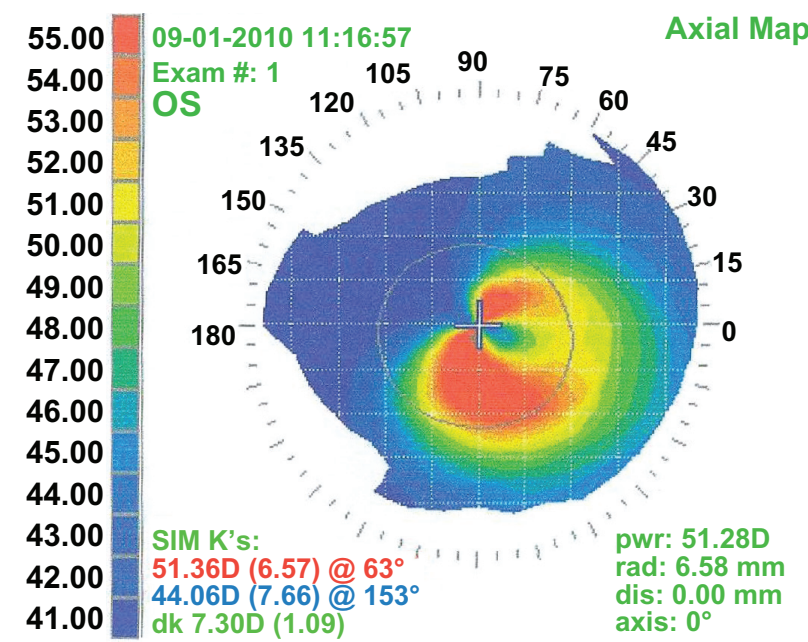

Figure I Corneal topography images of patient I (A) right eye and (B) left eye and patient 2 (C) right eye and (D) left eye. 
positive and negative values. Therefore, studies concerning the determination of keratoconus or keratoconus suspects usually use combined topographical indices to confirm the presence of the disorder. ${ }^{4,7}$

In the present study, the SRAX index demonstrated the lowest sensitivity, the AST index had the lowest specificity, and the $\mathrm{K}$ and I-S values were also associated with low specificity. These results suggest that using a single topographic index for the determination of keratoconus would result in variation of diagnosis, ie, higher rates of false positive and/or false negative diagnosis than using multiple indices for assessment of patients. However, the KISA\% index demonstrated sensitivity and specificity of $96 \%$ and $100 \%$, respectively, in terms of keratoconus diagnosis. These results are comparable to those reported in the study carried out by Rabinowitz and Rasheed, ${ }^{9}$ who demonstrated that with a cut-off value of $100 \%$, KISA $\%$ determined the correct diagnosis in $99.6 \%$ of cases.

It is tempting to suggest that the KISA\% index should be used in place of other topographical indices such as the $\mathrm{K}$ value, I-S value, SRAX, and AST, used alone or in combination. However, data from a study carried out by $\mathrm{Li}$ et $\mathrm{al}^{16}$ in which the $\mathrm{K}$ value, I-S value, and KISA \% indices were used to detect keratoconus in a group of normal individuals, keratoconus suspects, and a group of patients with early keratoconus, reported a total classification rate of $68.9 \%$. Therefore, although the present study demonstrates that the KISA\% index is significantly more sensitive and specific than other topographical indices, further research is required to confirm this conclusion in early-stage disease and suspected cases of keratoconus with no clinical symptoms. Until that time, KISA\% should be used in combination with other indices for the diagnosis and detection of keratoconus.

\section{Disclosure}

The authors report no conflicts of interest in this work.

\section{References}

1. Nordan LT. Keratoconus: diagnosis and treatment. Int Ophthalmol Clin. 1997;37(1):51-63.

2. Missotten L. Corneal topography. Curr Opin Ophthalmol. 1994;5(4): 68-74.

3. Maguire LJ, Bourne WM. Corneal topography of early keratoconus. Am J Ophthalmol. 1989;108(2):107-112.

4. Claude S, Verdier R, Arnaud B, Schmitt-Bernard CF. Accuracy of videokeratographic quantitative criteria for detection of keratoconus suspects in families with keratoconus. $J$ Fr Ophtalmol. 2004;27(7): 773-778.

5. Dumitrica DM, Colin J. Indices for the detection of keratoconus. Oftalmologia. 2010;54(2):19-29.

6. Solis-Vivanco A, Hernandez-Quintela E, Fromow-Guerra JJ, Cruz-Sanchez A, Ponce-de-Leon S, Naranjo-Tackman R. Corneal topography as a screening method for keratoconus suspects. Invest Ophthalmol Vis Sci. 2002;43:e-Abst 172.

7. Rabinowitz YS. Videokeratographic indices to aid in screening for keratoconus. J Refract Surg. 1995;11(5):371-379.

8. Mato JL, Lema I, Díez-Feijoo E. Videokeratoscopic indices in relation to epidemiological exposure to keratoconus. Graefes Arch Clin Exp Ophthalmol. 2010;248(7):991-998.

9. RabinowitzYS, Rasheed K. KISA\% index: a quantitative videokeratography algorithm embodying minimal topographic criteria for diagnosing keratoconus. J Cataract Refract Surg. 1999;25(10):1327-1335.

10. Sedghipour MR, Mostafaei A, Taghavi Y. Low-dose subconjunctival bevacizumab to augment trabeculectomy for glaucoma. Clin Ophthalmol. 2011;5:797-800.

11. Sedghipour MR, Sorkhabi R, Shenasi A, Dehghan H. Outcome of penetrating keratoplasty in corneal ulcer: a single-center experience. Clin Ophthalmol. 2011;5:1265-1268.

12. Krachmer JH, Feder RS, Belin MW. Keratoconus and related noninflammatory corneal thinning disorders. Surv Ophthalmol. 1984;28(4): 293-322.

13. Lee LR, Hirst LW, Readshaw G. Clinical detection of unilateral keratoconus. Aust N Z J Ophthalmol. 1995;23(2):129-133.

14. Leibowitz HM, Waring GO. Corneal Disorders: Clinical Diagnosis and Management. 2nd ed. Philadelphia, PA: WB Saunders; 1998.

15. Altman DG, Bland JM. Diagnostic tests 2: Predictive values. BMJ. 1994;309(6947):102

16. Li X, Yang H, Rabinowitz YS. Keratoconus: classification scheme based on videokeratography and clinical signs. J Cataract Refract Surg. 2009;35(9):1597-1603.
Clinical Ophthalmology

\section{Publish your work in this journal}

Clinical Ophthalmology is an international, peer-reviewed journal covering all subspecialties within ophthalmology. Key topics include: Optometry; Visual science; Pharmacology and drug therapy in eye diseases; Basic Sciences; Primary and Secondary eye care; Patient Safety and Quality of Care Improvements. This journal is indexed on Submit your manuscript here: http://www.dovepress.com/clinical-ophthalmology-journal

\section{Dovepress}

PubMed Central and CAS, and is the official journal of The Society of Clinical Ophthalmology (SCO). The manuscript management system is completely online and includes a very quick and fair peer-review system, which is all easy to use. Visit http://www.dovepress.com/ testimonials.php to read real quotes from published authors. 